\title{
Incidence of lymphohaematopoietic malignancies in a petrochemical industry cohort: 1983-94 follow up
}

\author{
Wendy W Huebner, Vivien W Chen, Barry R Friedlander, Xiao C Wu, Gail Jorgensen, \\ Faiyaz A Bhojani, Craig H Friedmann, Beth A Schmidt, Eugene A Sales, Javed A Joy, \\ Catherine N Correa
}

Epidemiology and Health Surveillance, Exxon Biomedical Sciences, 1545 Route 22, PO Box 971, Annandale, New Jersey 08801-0971, USA W W Huebner G Jorgensen

E A Sales

Louisiana Tumor Registry, Department of Public Health and Preventive Medicine, Louisiana State University Medical Center, 1600 Canal Street, Box 106, New Orleans, Louisiana 70112, USA

V W Chen

$\mathrm{X} \mathrm{C} \mathrm{Wu}$

B A Schmidt

J A Joy

C N Correa

Princeton Health Data, Princeton, NJ, USA

B R Friedlander

Medical and Occupational Health Department, Exxon Corporation, Houston, Texas, USA

F A Bhojani

International Medical and Occupational Health Department, Exxon Corporation, Florham Park, NJ, USA

C H Friedmann

Correspondence to: Dr W W Huebner wwhuebn@erenj.com

Accepted 18 May 2000

\begin{abstract}
Objectives-In response to a previous finding of increased mortality from lymphohaematopoietic (LH) malignancies, this study examines incidence of LH malignancy in a petrochemical industry cohort. Emphasis is on chronic lymphocytic leukaemia (CLL) and on comparisons by period of first employment. Method-The study cohort consists of 8942 employees who were active in the period 1970-92 and alive on 31 December 1982. Record linkage with the Louisiana tumour registry (LTR) provided information on cancer for cases occurring between 1983 and 1994. Standardised incidence ratios (SIR), with the south Louisiana population as a comparison, were computed for all cancers, all LH malignancies and specific LH subtypes. Analyses were conducted for sex and race categories, and by period of first employment, job type, duration of employment, and latency.
\end{abstract}

Results-672 Cases of cancer were identified, including 59 LH malignancies. Women $(n=1169)$ had an overall cancer SIR below unity and four LH malignancies versus 2.28 expected. Among the 7773 men, those first employed before 1950 had no overall cancer excess, a significant 1.4fold increase in overall LH malignancies (43 observed versus 30.78 expected), and four CLL cases versus 3.27 expected. Findings for men first employed after 1950 are based on fewer cases, but there was no indication of excesses of overall cancer or LH malignancy. Numbers were too small in the group first employed after 1950 for meaningful analysis of LH malignancy subtypes such as CLL (one case).

Conclusion-These findings do not suggest a continuing excess of CLL but do suggest a small increase in incidence of overall LH malignancy for workers first employed before 1950 . This may reflect associations with earlier workplace conditions, although work related patterns are mixed. Interpretation is limited by the diverse group of diseases within LH malignancies, and the lack of control for non-work factors other than sex, age, race, and period of diagnosis. This study has a major advantage of more complete and reliable cancer ascertainment compared with the mortality investigation, and shows the feasibility and benefits of using cancer registry incidence data in an occupational cohort study.

(Occup Environ Med 2000;57:605-614)

Keywords: petroleum industry; lymphohaematopoietic; chronic lymphocytic leukaemia; incidence

A recent study found a significant, 3.5-fold increase $(95 \%$ confidence interval (95\% CI) 1.68 to 6.45$)$ in deaths from chronic lymphocytic leukaemia (CLL) among male workers at a refinery and chemical plant in Baton Rouge, Louisiana. ${ }^{1}$ Ten deaths from CLL were found compared with $<3$ expected deaths based on the Louisiana male population. All CLL decedents were first employed before 1950 and had at least some work in refinery or chemical plants as handymen, mechanics, or operators. No obvious patterns were found with specific jobs or work areas. Lower, non-significant increases were found for other lymphohaematopoietic ( $\mathrm{LH})$ malignancies, including non-Hodgkin's lymphoma (12 observed versus nine expected) and acute myelocytic leukaemia (eight observed versus five expected).

We decided that a study of cancer incidence would be the most effective way to follow up the mortality study, for several reasons: (a) a case-control study of specific exposures in workers first employed before 1950 was not feasible; (b) a cancer incidence study could examine risk in more recent workers as well; and (c) cancer incidence studies examine a more complete range of cases (fatal and non-fatal ) with generally more reliable and detailed cancer diagnoses. Fortunately, Louisiana has a high quality, population based tumour registry that covers Baton Rouge, and former workers typically continue to reside in Louisiana where their cancers would be registered.

This study examines whether the incidence of CLL and other LH malignancies is consistent with previous mortality findings, and evaluates possible effects of period of first employment and other surrogates of exposure.

\section{Methods}

STUDY POPULATION AND DATA ON EMPLOYEES Eligible subjects were drawn from two existing company cohorts that contained employees from the Baton Rouge facility: (a) refinery and chemical plant workers from three United 
States locations who worked for at least 1 month during 1970-82 $2-4$; and (b) United States based employees who worked for at least a day between 1979 and $1992 .^{5}$ Both source cohorts were defined from company payroll records and are fully described elsewhere. ${ }^{245}$ Other inclusion criteria for the present cohort were being alive on 31 December 1982, and having current or final company employment at Baton Rouge or some active Baton Rouge employment during the 1983-94 study period. Before analysis, 167 people were excluded, including employees residing in the neighbouring state of Mississippi , those of "other race" (other than white or African-American), and one person with a cancer diagnosis before employment. The final study population was 8942.

All demographic and work history data were obtained from company payroll records. Work histories for the older refinery and chemical worker cohort were limited to start and stop dates for Baton Rouge work periods and an abstracted "most common" job category-for example, process operator. By contrast, the more recent source cohort had detailed work history records from 1979 forward, including all changes in general job location and job category: $53 \%$ of subjects are in both source cohorts. To capture earlier and presumably more exposed jobs, analyses of job type used the most common job category when possible and job category at first employment for those only in the more recent source cohort.

A retirement benefits database contained last known address for $57 \%$ of retired workers in the present study. The company payroll database included final postal address for $65 \%$ of workers who had left work before retirement. Address information was more likely to be missing for employees who left the company before 1979 .

Information on specific exposures and potentially confounding factors (other than age, sex, and race) was not available on a consistent basis for this cohort.

DATA ON CANCER INCIDENCE

The Louisiana tumour registry (LTR) provided information on: primary site, histology, behaviour, sequence (first or subsequent primary), diagnostic confirmation, date of diagnosis, and county (parish) of residence. The LTR staff performed record linkage for the period of 1983 (earliest year of available records) to the end of 1994. Data on cancer incidence for north Louisiana were not available for years before 1988 .

The LTR performs active surveillance by collecting cancer data from hospital records, and also obtains cancer information from several other medical sources. Louisiana death certificates are also routinely checked by the LTR for deaths from cancer. Those not already registered as incidence cases are followed back for additional information, and if none is found, are registered as death certificate only cases in LTR.
DATA PROTECTION AND DATA QUALITY

The study protocol was approved by the Institutional Review Board (IRB) at the Louisiana State University Medical Center. The collaborative company and registry research team developed a memorandum of agreement and procedures to ensure data security and protect privacy of study subjects. Study procedures were carried out according to the good epidemiology practices developed under the Chemical Manufacturers' Association. ${ }^{6}$

All work history records were systematically reviewed for accuracy and logic, with manual review of inconsistent records and decisions made by the same epidemiologist and analyst team. The LTR data have been subject to extensive quality control procedures ${ }^{7}$ and have met high quality standards for inclusion in national and international summaries of cancer registry data. ${ }^{8}$

\section{ANALYSIS}

Subjects entered into follow up on 1 January 1983 or date of first employment, whichever was later. Standardised incidence ratios (SIRs) were calculated as observed/expected cases of cancer. A modified life table approach was used to determine expected numbers by multiplying person-years at risk, stratified by sex, race (white or black), five year groupings of age, and intervals of year of diagnosis (1983-7, 198892, 1993-4), by the corresponding south Louisiana cancer incidences. All analyses used the occupational cohort mortality analysis program (OCMAP) from the University of Pittsburgh, ${ }^{10}$ with modifications to accommodate a cancer incidence analysis. The SIRs (95\% CI) were calculated in OCMAP with an exact method ${ }^{11}$ for results with at least five observed or five expected cases.

The SIR analyses were performed for sex/race categories and for surrogates of general exposure including period of first employment, job type, duration of employment, and time from first employment to diagnosis (latency). A cut off point of before 1950 and $\geqslant 1950$ was chosen for period of first employment, based on the previous mortality study in which all CLL decedents were first employed before 1950. Considering the uncertainties about latency periods and durations of exposure for various $\mathrm{LH}$ malignancies, and the wide range of latencies and durations in our study cohort, we chose conventional 20 year cut off points for these analyses.

The LTR provided incidences for overall cancer and LH malignancies and subtypes. For ease of use in the OCMAP software, rates were converted from international classification of diseases (ICD) oncology codes used by the LTR (ICD-O-1 for 1983-87 and ICD-O-2 for 1988-94), to ICD 9th revision (ICD-9) codes. $^{12-14}$ Most LH categories were determined by conventional ICD-9 groupings, except for non-Hodgkin's lymphoma (NHL) which was possible to define more precisely with the specific morphological codes of ICD$\mathrm{O}-2$.

As the LTR cancer incidences include multiple primaries, observed counts for SIR 
Table 1 Characteristics of final study cohort*

\begin{tabular}{lc}
\hline Characteristic & $n(\%)$ \\
\hline Total & $8942(100)$ \\
Sex/race: & \\
Male/white & $6673(75)$ \\
Male/black & $1100(12)$ \\
Female/white & $934(10)$ \\
Female/black & $235(3)$ \\
Decade of birth: & \\
$1900-9$ & $235(3)$ \\
$1910-9$ & $1321(15)$ \\
$1920-9$ & $985(11)$ \\
$1930-9$ & $475(5)$ \\
$1940-9$ & $2489(28)$ \\
$1950-9$ & $2651(30)$ \\
$1960-9$ & $768(8)$ \\
$\geqslant 1970$ & $18(<1)$ \\
Job type: & \\
Officials, managers & $263(3)$ \\
Professionals & $1835(20)$ \\
Technicians & $962(11)$ \\
Office or clerical & $597(7)$ \\
Process operators & $2187(24)$ \\
Mechanical workers & $2598(29)$ \\
Other† & $500(6)$ \\
Decade of first employment at Baton Rouge: & \\
$1920-9$ & $81(1)$ \\
$1930-9$ & $371(4)$ \\
$1940-9$ & $1669(19)$ \\
$1950-9$ & $364(4)$ \\
$1960-9$ & $1379(15)$ \\
$1970-9$ & $2695(30)$ \\
$1980-9$ & $1745(20)$ \\
$1990-2$ & $638(7)$ \\
Age at entry into follow up: & \\
$<30$ & $2082(23)$ \\
$30-9$ & $3350(37)$ \\
$40-9$ & $854(10)$ \\
$50-9$ & $693(8)$ \\
$60-9$ & $1400(16)$ \\
$70-9$ & $563(6)$ \\
\hline & \\
\hline & \\
&
\end{tabular}

*Total was 9109 cohort members before exclusions of Mississippi residents and other race.

†Includes service workers, labourers, and missing people.

calculations included them as well. Follow up time was handled as follows: (a) for overall cancer and all LH malignancies, follow up continues past the date of diagnosis to account for the possibility of another primary cancer; and $(b)$ for specific cancer subtypes, follow up ends at date of diagnosis, because the LTR does not register the same LH subtype as a second primary, according to rules of surveillance, epidemiology, and end results (SEER). ${ }^{15}$ A National Death Index search was conducted to the end of 1994 to provide precise end points of follow up time for cohort members who died during the study period.

Table 2 Number of subjects (men and women) diagnosed with cancer by job status, period of first employment, and job type

\begin{tabular}{|c|c|c|c|}
\hline Characteristic & $\begin{array}{l}\text { Subjects } \\
(n)\end{array}$ & $\begin{array}{l}\text { Subjects } \\
\text { with cancer } \\
\text { (n) }\end{array}$ & $\begin{array}{l}\text { Percentage of } \\
\text { all subjects with } \\
\text { cancer }\end{array}$ \\
\hline \multicolumn{4}{|c|}{ Job status at end of follow up: } \\
\hline Active workers & 4126 & 31 & 5 \\
\hline Retired workers & 2732 & 564 & 90 \\
\hline Left work & 2043 & 31 & 5 \\
\hline Died while employed & 41 & 2 & $<1$ \\
\hline \multicolumn{4}{|l|}{ Period of first employment: } \\
\hline$<1950$ & 2121 & 489 & 78 \\
\hline$\geqslant 1950$ & 6821 & 139 & 22 \\
\hline \multicolumn{4}{|l|}{ Job type: } \\
\hline Process operators & 2187 & 145 & 23 \\
\hline Mechanical workers & 2598 & 228 & 36 \\
\hline Technicians & 962 & 58 & 9 \\
\hline Office based workers ${ }^{\star}$ & 2695 & 132 & 21 \\
\hline Othert & 500 & 65 & 10 \\
\hline Total & 8942 & $628 \ddagger$ & 100 \\
\hline
\end{tabular}

${ }^{\star}$ Managers, professionals, office, or clerical workers.

†Service workers, labourers, or missing people.

$\ddagger$ Total cases of cancer $=672$, considering multiple primaries.
If cohort members migrated from Louisiana after employment ended or when out of state gaps occurred during active employment, person-time in Louisiana was over counted, leading to overestimated expected numbers and underestimated SIRs. A stepped analytical approach was taken to counteract this potential bias. An initial analysis assumed that all time after leaving work was spent residing in Louisiana. Subsequent analyses truncated persontime spent outside Louisiana as indicated in work histories and available (albeit incomplete) address information for retired workers and those who left the company before retirement. Four conditions for truncating person-time were applied. (1) All time after Baton Rouge employment, if the last job in the company was not in Baton Rouge. (2) Any gaps between two periods of Baton Rouge employment. (3) Any known non-Louisiana residence after retirement. (Among the 1546 retired workers with known addresses, time after leaving work was truncated for $98(6 \%)$ with a non-Louisiana address.) (4) Any known non-Louisiana residence after leaving the company without retiring. (Among 1330 workers with a known last address, time after work was truncated for 359 $(27 \%)$ with a non-Louisiana address.)

These truncations resulted in the elimination of $8 \%$ of person-time and loss of eight cases of cancer (none were LH malignancies). The resulting increases in SIRs for the entire cohort were $2 \%$ for all cancers and $5 \%$ for all $\mathrm{LH}$ malignancies, and for men, $3 \%$ and $4 \%$, respectively. Subsequent analyses applied the four conditions for truncating person-time (reported in this paper).

\section{Results}

POPULATION CHARACTERISTICS AND CASES OF CANCER

The study cohort was predominantly male and white, with about a third born before 1940, and most others born in the 1940s and 1950s (table 1). There was low recruitment in the 1950 s and peak hiring in the 1970 s. About $60 \%$ of the cohort had first job (and usually all jobs) as operators, mechanical workers, or other plant jobs. Another 30\% were professional and technical. Sixty per cent of subjects entered into follow up before the age of 40, and active work time accounts for $62 \%$ of follow up time during the study period. The (mean) duration of follow up was 9.6 years for workers first employed before 1950 and 10.5 years for those first employed in 1950 or later.

A total of 672 cases of cancer among 628 people were identified, including 586 single, 40 double, and two triple primaries. Men had 643 (96\%) of the total 672 cases of cancer and contribute 80000 of the total 92000 person-years of follow up. As seen in table 2, retired workers comprised only $31 \%$ of the cohort but had $90 \%$ of the cancers, and workers first employed before 1950 comprised $24 \%$ of the cohort and had almost $80 \%$ of the cancers. Cancer distributions by job type were generally similar to the proportions of the cohort in each category-for example, 54\% of cohort 
Table 3 Total number of incident lymphohaematopoietic malignancies and diagnostic descriptions: total cohort

\begin{tabular}{|c|c|c|}
\hline Type of malignancy (ICD-9 codes) & $\begin{array}{l}\text { Cases } \\
(n)\end{array}$ & $\begin{array}{l}\text { Diagnostic descriptions (morphology) according to ICD oncology } \\
\text { classification }\end{array}$ \\
\hline All lymphohaematopoietic malignancies (200-208) & 59 & \\
\hline Hodgkin's disease (201) & 5 & $\begin{array}{l}\text { Lymphocytic or histiocytic predominance, not otherwise stated ( } 2 \\
\text { cases) } \\
\text { Nodular sclerosis, not otherwise stated ( } 3 \text { cases) }\end{array}$ \\
\hline $\begin{array}{l}\text { Non-Hodgkin's lymphoma }{ }^{\star}(200.0-200.2,200.8,202.0,202.1,202.2,202.8 \text {, } \\
\text { 202.9) }\end{array}$ & 25 & \\
\hline Reticulosarcoma (200.0) & $(8)$ & $\begin{array}{l}\text { Malignant lymphoma, large cell, histiocytic, diffuse ( } 6 \text { cases }) \\
\text { Malignant lymphoma, histiocytic reticulum cell type }(2 \text { cases })\end{array}$ \\
\hline Lymphosarcoma (200.1) & (3) & $\begin{array}{l}\text { Malignant lymphoma, lymphocytic ( } 2 \text { cases }) \\
\text { Malignant lymphoma, small cleaved cell ( } 1 \text { case) }\end{array}$ \\
\hline Nodular or follicular (202.0) & (5) & Nodular or follicular (5 cases) \\
\hline Other named variants (200.8) & (7) & $\begin{array}{l}\text { Lymphoplasmacytoid type ( } 2 \text { cases }) \\
\text { Immunoblastic type }(4 \text { cases) } \\
\text { Mixed small and large cell, diffuse ( } 1 \text { case) }\end{array}$ \\
\hline T-cell lymphoid variety $(202.1,202.2)$ & (1) & 202.2 - Sezary's disease ( 1 case) \\
\hline Other lymphomas (202.8) & (1) & Malignant lymphoma, not otherwise stated (1 case) \\
\hline Multiple myeloma (203.0) & 9 & \\
\hline Leukaemia (204-208) & 17 & \\
\hline Acute non-lymphocytic (ANLL) $(205.0,206.0,207.0,207.2)$ & $(4)$ & $\begin{array}{l}205.0 \text { Acute myeloid (granulocytic or myelocytic) ( } 3 \text { cases) } \\
205.0 \text { Acute promyelocytic ( } 1 \text { case) }\end{array}$ \\
\hline Chronic myelocytic (CML) (205.1) & (4) & Chronic myelocytic or myelomonocytic ( 4 cases) \\
\hline Acute lymphocytic (ALL) (204.0) & (2) & Acute lymphocytic ( 2 cases) \\
\hline Chronic lymphocytic (CLL) (204.1) & (5) & Chronic lymphocytic (5 cases) \\
\hline Other and unspecified leukaemia (all other 204-208) & $(2)$ & $\begin{array}{l}\text { 208.0 Acute leukaemia, not otherwise stated ( } 1 \text { case) } \\
\text { 208.9 Leukaemia, not otherwise stated ( } 1 \text { case) }\end{array}$ \\
\hline $\begin{array}{l}\text { Lymphohaematopoietic malignancies not in main groupingst }(202.3,202.4 \text {, } \\
202.5,202.6,203.1,203.8)\end{array}$ & 3 & $\begin{array}{l}\text { 202.4 B-Cell lymphoid variety } \\
\text { Leukaemic reticuloendotheliosis: hairy cell leukaemia (2 } \\
\text { cases) } \\
\text { 203.8 Other immunoproliferative malignancies } \\
\text { Plasmacytoma, not otherwise stated (1 case) }\end{array}$ \\
\hline
\end{tabular}

^Non-Hodgkin's lymphoma (NHL) according to the SEER definition in ICD-0-2, which includes morphology codes M9590-9595 and M9670-9715 (all sites). These codes were converted to the ICD-9 codes listed in the table under NHL.

†These conditions are not part of the lymphoma, leukaemia, or multiple myeloma categories defined in this study (see methods text).

members were process operators or mechanical workers, and contributed $59 \%$ of cancers).

CHARACTERISATION OF CASES OF

LYMPHOHAEMATOPOIETIC MALIGNANCY

Fifty nine cases of LH malignancy were identified among 58 people. Table 3 shows diagnostic categories, counts, and morphological descriptions of these cases. Non-Hodgkin's lymphoma accounted for $42 \%$ of total $\mathrm{LH}$ cases, leukaemia for $29 \%$, and multiple myeloma for $15 \%$. The predominant NHL subtype was reticulosarcoma, primarily of the histiocytic cell type. Chronic leukaemias were more common than acute leukaemias.
We examined diagnostic agreement among the 35 incident cases of LH malignancy that also had company death certificate records. Seven incident cases of $\mathrm{LH}$ had non-LH underlying causes of death. Among the remaining 28 for whom LH diagnoses could be compared, 10 had an LH match to the fourth digit of ICD-9, four matched to the third digit, and the other 14 matched only to the broad LH category-for example, leukaemia. Notably, nine of the 10 cases with cause of death in the non-specific category of other lymphomas (ICD 202.8), had LTR diagnoses in more specific categories of reticulosarcoma or lymphosarcoma (ICD 200.0 and 200.1). Only one LH

Table 4 Observed/expected, standardised incidence ratios (SIR) (95\% CIs) white and black men

\begin{tabular}{|c|c|c|}
\hline Type of malignancy & $\begin{array}{l}\text { Observed/ } \\
\text { Expected }\end{array}$ & $\operatorname{SIR}(95 \% C I)$ \\
\hline All malignant neoplasms $\star$ & $637 / 656.84$ & $0.97(0.90$ to 1.05$)$ \\
\hline Malignant neoplasms of lymphatic and haematopoietic tissue (200-208) & $55 / 46.56$ & $1.18(0.89$ to 1.54$)$ \\
\hline Hodgkin's disease (201.0-201.9) & $4 / 2.59$ & - \\
\hline Non-Hodgkin's lymphoma (NHL) $(200.0,200.1,200.2,200.8,202.0,202.1,202.2,202.8,202.9)$ & $22 / 20.64$ & $1.06(0.67$ to 1.61$)$ \\
\hline Reticulosarcoma (200.0) & $5 / 4.46$ & $1.12(0.36$ to 2.62$)$ \\
\hline Lymphosarcoma (200.1) & $3 / 3.81$ & - \\
\hline Burkitt's lymphoma (200.2) & $0 / 0.06$ & - \\
\hline Other named variants (200.8) & $7 / 3.59$ & $1.95(0.78$ to 4.02$)$ \\
\hline Nodular or follicular (202.0) & $5 / 3.13$ & $1.60(0.51$ to 3.73$)$ \\
\hline T-cell lymphoid (202.1-mycosis fungoides, 202.2-Sezary's disease) & $1 / 0.33$ & - \\
\hline Other lymphomas (202.8) & $1 / 5.20$ & $0.19(0.005$ to 1.07$)$ \\
\hline Multiple myeloma (203.0) & $9 / 6.48$ & $1.39(0.64$ to 2.64$)$ \\
\hline Leukaemia (204-208) & $17 / 13.16$ & $1.29(0.75$ to 2.07$)$ \\
\hline ANLL $(205.0,206.0,207.0,207.2)$ & $4 / 4.22$ & - \\
\hline CML (205.1) & $4 / 2.21$ & - \\
\hline ALL (204.0) & $2 / 0.67$ & - \\
\hline CLL (204.1) & $5 / 4.10$ & $1.22(0.40$ to 2.85$)$ \\
\hline Other and unspecified leukaemia $(204.2,204.8,204.9,205.2,205.3,205.8,205.9,206.1,206.2,206.8$, & & \\
\hline $206.9,207.1,207.8,208.0,208.1,208.2,208.8,208.9$ & $2 / 1.96$ & - \\
\hline Lymphohaematopoietic malignancies not in main groupings $(202.3-202.6,203.1,203.8) \ddagger$ & $3 / 0.70$ & - \\
\hline B-cell (202.4 hairy cell leukaemia), 203.1 plasma cell leukaemia) & $2 / 0.38$ & - \\
\hline Other $(202.3,202.5,202.6,203.8)$ & $1 / 0.32$ & - \\
\hline
\end{tabular}

*All analyses consider multiple primaries (see methods text). SIRs are calculated only if there are at least five observed cases or five expected.

†NHL is defined according to the SEER ICD-0-2 codes, which includes morphology codes M9590-9595 and M9670-9715 (all sites). These codes were converted to the ICD-9 codes listed in the table.

¥These conditions are not part of the lymphoma, leukaemia, or multiple myeloma categories defined in this study (see methods text). 


\begin{tabular}{|c|c|}
\hline Characteristic & $n(\%)$ \\
\hline \multicolumn{2}{|l|}{ Race: } \\
\hline White & $46(85)$ \\
\hline Black & $8(15)$ \\
\hline \multicolumn{2}{|l|}{ Decades of birth: } \\
\hline $1900-19$ & $37(68)$ \\
\hline $1920-39$ & $8(15)$ \\
\hline $1940-59$ & $9(17)$ \\
\hline \multicolumn{2}{|l|}{ Job type: } \\
\hline Process operator & $16(30)$ \\
\hline Mechanical & $18(33)$ \\
\hline Technician & $5(9)$ \\
\hline Office ${ }^{\star}$ & $10(18)$ \\
\hline Othert & $5(9)$ \\
\hline \multicolumn{2}{|c|}{ Period of first employment at Baton Rouge } \\
\hline $1920-39$ & $16(30)$ \\
\hline $1940-49$ & $26(48)$ \\
\hline$\geqslant 1950$ & $12(22)$ \\
\hline \multicolumn{2}{|c|}{ Duration of employment (y): } \\
\hline$<20$ & $9(17)$ \\
\hline $20-39$ & $38(70)$ \\
\hline$\geqslant 40$ & $7(13)$ \\
\hline \multicolumn{2}{|c|}{$\begin{array}{l}\text { Latency (first employment at Baton Rouge to year of } \\
\text { diagnosis, y): }\end{array}$} \\
\hline$<20$ & $7(13)$ \\
\hline $20-39$ & $9(17)$ \\
\hline$\geqslant 40$ & $38(70)$ \\
\hline \multicolumn{2}{|l|}{ Age at diagnosis: } \\
\hline $30-49$ & $9(17)$ \\
\hline $50-69$ & $9(17)$ \\
\hline$\geqslant 70$ & $36(67)$ \\
\hline \multicolumn{2}{|l|}{ Period of diagnosis: } \\
\hline $1983-87$ & $18(33)$ \\
\hline $1988-92$ & $25(46)$ \\
\hline $1993-94$ & $11(20)$ \\
\hline
\end{tabular}

^Supervisor, professional, office, or clerical worker. †Service workers, labourers, and missing people.

case had a less specific LTR diagnosis (other leukaemia, ICD 208.0, versus acute myelocytic leukaemia (AML), ICD 205.0, on the death certificate).

RESULTS OF STANDARDISED INCIDENCE RATIO (SIR) ANALYSES

Overall SIR analysis

The SIR analyses reported here applied the four conditions for truncating person-time (see methods) and examined 664 cases of cancer, including $59 \mathrm{LH}$ malignancies. The 1169 white and black women had an SIR below unity for all cancers (SIR $0.86,95 \%$ CI 0.56 to 1.25 ),

Table 6 Observed/expected, standardised incidence ratios (SIRs) (95\% CIs) for white and black men by period of first employment

\begin{tabular}{|c|c|c|}
\hline Type of malignancy & First employed $<1950$ & First employed $\geqslant 1950$ \\
\hline All malignant neoplasms & $516 / 495.61$ & $121 / 161.24$ \\
\hline All lymphohaematopoietic neoplasms $\dagger$ & $\begin{array}{l}43 / 30.78 \\
1.40^{\star}(1.01 \text { to } 1.88)\end{array}$ & $\begin{array}{l}12 / 15.78 \\
0.76(0.39 \text { to } 1.33)\end{array}$ \\
\hline Hodgkin's disease & $2 / 0.75$ & $2 / 1.83$ \\
\hline Non-Hodgkin's lymphoma (SEER) & $\begin{array}{l}18 / 12.52 \\
1.44(0.85 \text { to } 2.27)\end{array}$ & $\begin{array}{l}4 / 8.11 \\
0.49(0.13 \text { to } 1.26)\end{array}$ \\
\hline Multiple myeloma & $\begin{array}{l}7 / 4.92 \\
1.42(0.57 \text { to } 2.93)\end{array}$ & $2 / 1.57$ \\
\hline Leukaemia & $\begin{array}{l}14 / 9.42 \\
1.49(0.81 \text { to } 2.49)\end{array}$ & $3 / 3.75$ \\
\hline ANLL & $3 / 2.90$ & $1 / 1.32$ \\
\hline CML & $4 / 1.40$ & $0 / 0.81$ \\
\hline ALL & $1 / 0.32$ & $1 / 0.34$ \\
\hline CLL & $4 / 3.27$ & $1 / 0.83$ \\
\hline Unspecified & $2 / 1.53$ & $0 / 0.44$ \\
\hline
\end{tabular}

${ }^{\star} \mathrm{p}<0.05 ;{ }^{\star \star} \mathrm{p}<0.01$.

+Total includes three additional lymphohaematopoietic malignancy cases that are not in the categories of lymphoma, leukaemia, or multiple myeloma (see methods text). based on 27 cases. Four cases were LH malignancies (versus 2.28 expected), of which three were reticulosarcoma (versus 0.22 expected). The three cases were office workers and had no patterns in period of first employment or work location. The small numbers precluded further analysis of women, and the rest of the report presents findings for men.

The SIR for overall cancer among the 7773 white and black men was 0.97 (table 4). For combined LH malignancies and broad LH categories, observed numbers were higher than expected numbers. The SIR for leukaemia did not include two cases of hairy cell leukaemia (202.4), which were classified as other lymphoid in ICD-9 but considered to be a leukaemia in ICD-O-2. When this category was included, the SIR for leukaemia increased from 1.29 to 1.40 and remained non-significant. For CLL, there were five observed cases versus 4.10 expected. The SIR for NHL was near 1.0 but varied by subtype, from 0.19 for other lymphomas (ICD 202.8) to 1.95 for other named variants (ICD 200.8).

Findings for white men, who had $89 \%$ of male cases, were essentially the same as for all men. Among black men there were 72 cases of cancer, including eight $\mathrm{LH}$ malignancies versus five expected. These included two cases of NHL, three multiple myeloma, and three leukaemia, all with observed numbers slightly larger than expected.

Table 5 shows demographic and job characteristics of the 54 men diagnosed with $\mathrm{LH}$ malignancies (one man had two LH diagnoses). Cases were predominantly born before 1920, first employed before 1950, employed for at least 20 years, and diagnosed after more than 40 years after first employment and at the age of 50 or older.

\section{Period of first employment}

Workers first employed before 1950 had an SIR near unity for overall cancer, and 1.4-fold increases across broad LH categories (table 6). Four of the five cases of CLL were first employed before 1950 (versus 3.27 expected). Workers first employed after 1950 had SIRs well below unity for overall cancer and all LH malignancies. Case numbers were small for LH categories, and the SIR for NHL was particularly low.

\section{Job type}

The SIRs for overall cancer and combined LH malignancies were near unity and similar across job type (table 7). Some LH categories had slight increases but $95 \%$ CIs were wide. Numbers were too small for meaningful analysis of leukaemia subtypes. The five CLL cases had jobs as process operator or labourer. A separate analysis by job type was done for workers first employed before 1950 (not shown), and findings were essentially the same as those in table 7 .

Time since first first employment (latency) and duration of employment

Most cases of cancer (80\%) occurred with a latency period $\geqslant 40$ years, which had a significant 1.5-fold increase for combined $\mathrm{LH}$ 
Table 7 Observedlexpected, standardised incidence ratios (SIRs) (95\% CIs) white and black men by job type

\begin{tabular}{|c|c|c|c|c|c|}
\hline Type of malignancy & Process operators & Mechanical workers & Technicians & Office based workers* & All otherst \\
\hline All malignant neoplasms & $157 / 161.39$ & $237 / 245.70$ & $65 / 59.21$ & $109 / 116.47$ & $69 / 74.07$ \\
\hline & $0.97(0.83$ to 1.14$)$ & $0.96(0.85$ to 1.10$)$ & $1.10(0.85$ to 1.40$)$ & $0.94(0.77$ to 1.13$)$ & $0.93(0.72$ to 1.18$)$ \\
\hline All lymphohaematopoietic neoplasms $\ddagger$ & $\begin{array}{l}16 / 12.09 \\
1.32(0.76 \text { to } 2 .\end{array}$ & $\begin{array}{l}18 / 17.09 \\
1.05(0.62 \text { to } 1.66)\end{array}$ & $\begin{array}{l}5 / 4.43 \\
1.13(0.36 \text { to } 2.63)\end{array}$ & $\begin{array}{l}11 / 8.56 \\
1.29(0.64 \text { to } 2.30)\end{array}$ & $\begin{array}{l}5 / 4.38 \\
1.14(0.37 \text { to } 2.66)\end{array}$ \\
\hline Hodgkin's disease & $0 / 0.75$ & $3 / 0.86$ & $0 / 0.27$ & $1 / 0.56$ & $0 / 0.15$ \\
\hline Non-Hodgkin's lymphoma (SEER) & $\begin{array}{l}5 / 5.51 \\
0.91(0.30 \text { to } 2.12)\end{array}$ & $\begin{array}{l}7 / 7.70 \\
0.91(0.37 \text { to } 1.87)\end{array}$ & $3 / 2.00$ & $\begin{array}{l}5 / 3.95 \\
1.27(0.41 \text { to } 2.95)\end{array}$ & $2 / 1.48$ \\
\hline Multiple myeloma & $4 / 1.45$ & $1 / 2.25$ & $\begin{array}{l}0 / 0.51 \\
-\end{array}$ & $3 / 1.00$ & $1 / 1.27$ \\
\hline Leukaemia & $\begin{array}{l}6 / 3.43 \\
1.75(0.64 \text { to } 3.81)\end{array}$ & $\begin{array}{l}6 / 5.01 \\
1.20(0.44 \text { to } 2.60)\end{array}$ & $2 / 1.20$ & $1 / 2.36$ & $2 / 1.15$ \\
\hline
\end{tabular}

^Includes supervisors, professionals, office, and clerical workers.

†Includes service workers, labourers, and missing people.

$\ddagger$ Total includes three additional cases of lymphohaematopoietic malignancy that are not in the categories of lymphoma, leukaemia, or multiple myeloma (see methods text).

malignancies and similar findings across broad LH categories (right column of table 8). Table 8 also shows SIRs for duration of employment in categories of $<20,20-39$, and $\geqslant 40$ years, within the latency period of $\geqslant 40$ years. For overall cancer and all LH malignancies, SIRs were closer to unity in the 20-39 year category (where most cases occurred), compared with higher SIRs in the $\geqslant 40$ years category. However, no patterns in diagnosis, job type, or work area were noted for the $12 \mathrm{LH}$ malignancy cases with $\geqslant 40$ years of employment.

We also examined latency effects among workers first employed in or after 1950 , for $<20$ years versus $\geqslant 20$ years since first employment (not shown). No marked differences were found, although small numbers precluded meaningful analysis for all but LH malignancies combined and overall cancer.

Finally, we checked for possibly underestimated SIRs due to inclusion of recently or briefly employed people who had not worked long enough or had enough time to develop a work related cancer. In three separate analyses that excluded all person-time of: $(a)<5$ years job duration; $(b)<10$ years job duration; or $(c)$ $<5$ years job duration and $<10$ years latency, there were virtually no changes in SIRs.

\section{$B$ cell malignancies}

A separate analysis was performed for combined $\mathrm{LH}$ categories of $\mathrm{B}$ cell origin, including CLL, multiple myeloma, selected NHL (reticulosarcomas and lymphosarcomas and nodular follicular lymphoma), hairy cell leukaemia, and plasma cell leukaemia. Twenty nine of the 55 cases of LH malignancy were B cell malignancies, versus 22.36 expected, for a non-significant SIR of 1.30. Results of analyses for period of first employment, latency, and duration of employment were generally similar to findings for all $\mathrm{LH}$ malignancies. Process operators had 13 observed cases versus 5.63 expected (significant) whereas mechanical workers had three observed cases versus 8.28 expected.

\section{Discussion}

Overall, we did not find the excesses of $\mathrm{LH}$ malignancy observed in the previous mortality study, although considerable differences were found in analyses by period of first employment. Findings were more stable for those first employed before 1950; meaningful analysis of later workers was limited to overall cancer and combined LH malignancies.

\section{ALL CANCER COMBINED}

The higher SIR for overall cancer among workers first employed before 1950 versus 1950 or later (1.04 and 0.75 , respectively) may be due to one or more of the following: $(a)$ diminished healthy worker effect in older workers; (b) somewhat higher proportions of plant versus office workers in the earlier group; and $(c)$ generally lower workplace hazards in more recent work environments.

Table 8 Observed/expected, standardised incidence ratios (SIRs) (95\% CIs) white and black men by duration of employment for latency category of $\geqslant 40$ years

\begin{tabular}{|c|c|c|c|c|}
\hline \multirow[b]{2}{*}{ Type of malignancy } & \multicolumn{4}{|c|}{ Latency of $\geqslant 40 y$} \\
\hline & $\begin{array}{l}\text { Duration of } \\
\text { employment } \\
\text { of }<20 y\end{array}$ & $\begin{array}{l}\text { Duration of } \\
\text { employment } \\
20-39 y\end{array}$ & $\begin{array}{l}\text { Duration of employment } \\
\geqslant 40 y\end{array}$ & $\begin{array}{l}\text { All durations of } \\
\text { employment }\end{array}$ \\
\hline \multirow[t]{2}{*}{ All malignant neoplasms } & $0 / 0.12$ & $377 / 366.05$ & $89 / 70.61$ & $466 / 436.78$ \\
\hline & & $1.03(0.93$ to 1.14$)$ & $1.26^{\star \star}(1.01$ to 1.55$)$ & $1.07(0.97$ to 1.17$)$ \\
\hline \multirow{2}{*}{ All lymphohaematopoietic neoplasms $\dagger$} & $0 / 0.01$ & $29 / 22.81$ & $12 / 4.37$ & $41 / 27.19$ \\
\hline & & $1.27(0.85$ to 1.83$)$ & $2.75^{\star}(1.42$ to 4.80$)$ & $1.51^{\star}(1.08$ to 2.05$)$ \\
\hline \multirow[t]{2}{*}{ Hodgkin's disease } & - & $1 / 0.58$ & $1 / 0.11$ & $2 / 0.69$ \\
\hline & 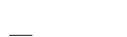 & $\overline{13} / 1022$ & $\overline{4 / 1} .93$ & $\overline{17} / 1215$ \\
\hline Non-Hodgkin's lymphoma (SEER) & - & $1.27(0.68$ to 2.18$)$ & - & $1.40(0.82$ to 2.24$)$ \\
\hline \multirow[t]{2}{*}{ Multiple myeloma } & - & $4 / 3.93$ & $3 / 0.81$ & $7 / 4.74$ \\
\hline & & - & - & $1.48(0.59$ to 3.04$)$ \\
\hline \multirow{2}{*}{ Leukaemia } & - & $9 / 7.73$ & $4 / 1.45$ & $13 / 9.18$ \\
\hline & & $1.16(0.53$ to 2.21$)$ & - & $1.42(0.75$ to 2.42$)$ \\
\hline
\end{tabular}

${ }^{\star} \mathrm{p}<0.05 ;{ }^{\star \star} \mathrm{p}<0.01$

†Total includes three cases of lymphohaematopoietic malignancy that are not in the categories of lymphoma, leukaemia, or multiple myeloma (see methods text). 
The SIR near 1.0 for overall cancer in the current study is similar to findings in the health watch study of more than 15000 male Australian petrochemical workers studied from 1981 to $1989^{16}$ and for a cohort of 9454 male and female Finnish oil refinery workers studied from 1971 to $1994 .{ }^{17}$ We also reviewed 27 studies of cancer incidence published since 1985 (identified by Whorton and Stout, as part of the Chemical Manufacturers' Association health studies inventory summary report, 1998) and found SIRs for overall cancer ranging from about 0.8 to 2.0 , with most between 0.9 and 1.2. Thus, overall cancer SIRs seemed generally higher than standardised mortality ratios (SMRs) which are typically around 0.85 in petroleum industry cohorts. ${ }^{18} 19$ This suggests that workers' better access to medical care has a different effect in studies of mortality and incidence - namely, a survival advantage in cancer mortality versus greater detection of cancer occurrence.

LYMPHOHAEMATOPOIETIC MALIGNANCIES

Of the 55 cases of LH malignancy detected in this study, 21 overlap with the previous mortality study; thus, these findings are not completely independent from the earlier study. The 1.4-fold increase of LH malignancies combined was found among workers first employed before 1950 and is similar for subtypes of NHL, multiple myeloma, and leukaemia, although non-significant. Work related patterns were mixed. The moderate associations with early first employment and with long latency could reflect greater exposures in earlier work eras. A duration of employment effect ( $\geqslant 40$ years latency) is also suggestive, although based on small numbers. Plant workers do not seem to have generally higher SIRs than office based workers, which argues against a workplace effect.

Alternate explanations for this result include chance and effects of one or more biases. A diagnostic bias is possible. ${ }^{20}$ During the 1970 s and 1980s, company physicians routinely referred cases of blood disorder to a haematology oncologist, and this may have increased the likelihood of diagnoses of LH malignancy in the cohort compared with the general population. Slightly increased SIRs may also be explained by uncontrolled confounding; we could not assess whether hypothesised risk factors such as previous infections, family history, or aspects of lifestyle may have a slight to moderate effect on the SIR. Finally, our ability to interpret this finding is limited by the separate disease entities and variety of possible aetiologies within LH malignancies.

In the published literature, results are mixed among the few reports of incidence of $\mathrm{LH}$ malignancy in petroleum workers. The Australian health watch study reported $26 \mathrm{LH}$ malignancies, including non-significant twofold increases for NHL and multiple myeloma, based on 10 and four cases, respectively, and a threefold excess for all leukaemia based on 12 cases (primarily myeloid leukaemia). ${ }^{16}$ The study of Finnish oil refinery workers reported 28 cases of NHL, leukaemia, and Hodgkins disease combined, with no leukaemia excess (nine cases) and a borderline significant twofold increase of NHL among male blue collar workers (SIR decreases with increasing duration of employment). ${ }^{17}$ An investigation of 19000 service station workers from four Nordic countries ${ }^{21}$ reported SIRs at 1.0 or below for all categories of LH malignancy, except for a non-significant SIR of 1.4 for AML (13 cases).

Most mortality studies of petroleum workers have SMRs near unity for combined LH malignancies, although many have slight to moderate increases for one LH subtype or another. ${ }^{18} 19$ These inconsistencies probably relate to coding problems as well as differences in exposures, varying cohort characteristics, and chance associations possibly resulting from multiple comparisons. Overall, considering the various, although inconsistent increases reported in the mortality publications and the established association between AML and high exposure to benzene, the possibility of some excess of LH malignancies among petroleum workers first employed before 1950 cannot be ruled out.

Study findings for workers first employed after 1950 are more relevant to recent workers and working conditions. Although the low SIR for LH malignancies combined was not significant, the upper confidence interval of 1.33 argues against substantially large risks. The SIRs remained low for latency periods of 20 years or more. Others have noted the difficulty of interpreting trends of decreasing risk with later employment, either jobs in later eras entail less risk, or more recent employees do not have sufficient latency or cumulative exposure. ${ }^{16}$ Such trends may also be explained by changes over time in factors of the study population versus the general population (case ascertainment, diagnoses, non-work related factors).

CHRONIC LYMPHOCYTIC LEUKAEMIA (CLL)

There is no overlap between the five incident cases of CLL in this study and the 10 CLL decedents found previously. The SIR near 1.0 for workers first employed before 1950 (four observed versus 3.27 expected) contrasts with the 3.5-fold mortality excess in the previous study. One possible explanation is that the mortality study shows a true increase in early workers from occupational or other risk factors; followed by a return to baseline occurrence of CLL for a latency period of $\geqslant 40$ years as found in the current incidence study.

An alternative explanation is that occurrence of CLL is not related to occupational settings in earlier eras, but that mortality detection or survival of CLL cases is somehow related to employment. One possibility is the diagnostic bias already discussed. Another possibility is that the higher mortality patterns that have been found among workers first employed during the second world war $^{22}{ }^{23}$ may be explained by their overall poorer health than those active in the war, or to differences in exposures or processes in wartime versus other periods. Attempts at more precise interpretations are speculative considering the complexities of 
directly comparing findings of incidence and mortality (differences in completeness of ascertainment and quality of diagnoses, variation between employed people and the general population, and the different periods of the two studies).

There are no clearly established relations between CLL and work in the petrochemical industry. In general, mortality analyses of petroleum worker cohorts have not suggested excess CLL. A meta-analysis of leukaemia subtypes among United States and United Kingdom petroleum worker cohorts found an overall non-significant SMR of 0.84 for CLL, based on 83 deaths. ${ }^{24}$ Since that review, an analysis of 81746 United States petrochemical company employees followed up from 1979 to 1992 found a non-significant increase of 1.81 for CLL among workers first employed before 1960 , with no patterns among the 11 cases in jobs or work locations. ${ }^{5}$ A 50 year mortality study of 17844 petrochemical workers in Texas found a significant deficit of three observed versus 10 expected deaths. ${ }^{25}$ Most recently, a 1947-93 follow up study of 28840 petroleum industry workers found a nonsignificant deficit of CLL (13 observed versus 15.8 expected) among white men first employed before $1950 .^{26}$

Information on incidence of CLL in petroleum workers is scant. The Australian health watch study reported four observed versus 1.4 expected cases of lymphocytic leukaemia. ${ }^{16} \mathrm{~A}$ non-significant SIR of 0.8 was reported for CLL among male service station workers (eight cases). ${ }^{21}$

A few focused case-control studies of CLL that considered (to a limited extent) specific exposures have not shown a consistent pattern of chemicals implicated. ${ }^{27-29}$ A more recent nested case-control study of petroleum distribution workers in the United Kingdom examined associations between leukaemia and quantitative estimates of personal exposure to benzene. ${ }^{30}$ Analysis of 31 cases of CLL and matched controls found associations with longer job duration and white collar work. These workers had only background exposure to benzene, and CLL did not increase with increasing exposure to benzene. Another nested case-control study of several petroleum company divisions found a non-significant odds ratio of 2.0 for lymphocytic leukaemia among workers in the marketing division, based on 10 cases in that division. ${ }^{31}$

NON-HODGKIN'S LYMPHOMA (NHL)

Although the overall SIR for NHL was an unremarkable 1.06, there was a deficit of the non-specific subtype of other lymphomas and an increase of a more specific subtype of other named variants. This may be explained by diagnostic and coding differences for cohort cases versus the general population: if a report for an otherwise non-specific malignant lymphoma (202.8) had any information about a specific cell type, it should have been coded to 200.8. As employed people are thought to have generally better access to medical care, this is probably an example of diagnostic sensitivity bias. $^{20}$

\section{B CELL MALIGNANCIES}

Results for B cell malignancies combined were essentially the same as for all LH malignancies, which does not lend support to recent suggestions of links between malignancies of lymphocytic cell lines and employment in the chemical industry. ${ }^{32}$ The increase in the present study among process operators contrasted with the unusually low SIR for mechanical workers; this may be due to misclassification of job type in early workers.

\section{STRENGTHS AND LIMITATIONS}

This cancer incidence study was more informative than the previous mortality analysis for several reasons. We were able to obtain more complete case enumeration which is especially important for cancers with relatively good survival. For example, 5 year survival of CLL was $71 \%$ in the United States during 1989-94. ${ }^{34}$ Another advantage is the generally more accurate and specific diagnostics of incidence cases, as found in our comparisons of diagnoses of LH cases between the LTR and death certificates. Study of incidence also entails less selection bias toward severe (fatal) cases, and the use of an earlier end point allows more timely study of relatively recent workers.

On the other hand, cancer incidence studies in the United States are limited by the lack of a national database. Reliance on a state cancer registry requires investigation of completeness of case catchment among state residents and among the study cohort. Regarding capture in the state, an external audit of the LTR ascertainment found a capture rate of $97.6 \%$ for the three cancer sites investigated. ${ }^{7}$

We were concerned that cohort cases may be missed in the 1983-7 period when north Louisiana did not have cancer registration, but north Louisiana's contribution to cohort cases seems to be minimal. Among 468 cases ascertained by the LTR for the cohort in 1988-94, only three were from north Louisiana $(0.65 \%)$; this suggests a negligible impact over the entire 1983-94 period. (Also, fewer than 1\% of the cohort's Louisiana deaths occurred in north Louisiana.)

Other indicators of good case capture in the study cohort are the reasonably similar findings for the cohort as for south Louisiana and the Baton Rouge region regarding: (a) distributions of broad LH categories; (b) mortality/ incidence ratios for all cancer and all $\mathrm{LH}$ malignancies; and (c) percentage of multiple primaries during 1983-94 (7\% in the study cohort versus $5.7 \%$ in south Louisiana).

Finally, we checked case capture by comparing the 291 company known cancer deaths to cases identified by the LTR. We found 223 matches, 11 out of state deaths, one death before 1988 in north Louisiana, and 56 unexplained non-matches. Since the LTR excludes death certificate only cases when evidence is found to rule out their inclusionfor example, diagnosis before the catchment 
period or non-Louisiana residence at diagnosis-these 56 cases may have been excluded for such reasons. Thirty seven of the 56 non-matches died within 5 years of the LTR catchment (1983) so their diagnoses may have preceded 1983. Among the other 19 (who died between 1988 and 1994), at least 11 had cancer types that could have long survival - for example, colon or prostate cancer. In the absence of diagnostic or address information to confirm or refute the LTR exclusions, we cannot rule out the possibility that some cohort cases were missed. But we have no reason to think that the proportion of missed cases would be different for the cohort than for the south Louisiana general population.

Another concern is migration of employees out of Louisiana. Our data suggest that potential for bias due to cohort migration is low. The strongest support is that according to place of death (state) on death certificates, only $4 \%$ of cohort deaths between 1970 and 1992 occurred outside Louisiana. Among retired workers with known addresses, only $6 \%$ lived outside Louisiana. Workers who left the company before retirement seemed to have migrated to a greater extent; among those with known departing address, $27 \%$ lived outside Louisiana. However, the impact of this migration on SIRs was probably low. We estimate that only $5 \%$ of the cohort's cases of cancer were among men who left work before retirement $(90 \%$ of their person-time was for age 50 and younger). Thus, migrants from this group may account for about $1 \%-2 \%$ of all cancers in the cohort. (We note that effects of these men will increase over time as they age and become more susceptible to developing cancer. For this reason, future analyses will need more complete determination of addresses after the end of employment.)

We also examined the potential impact of differential health status of migrants versus non-migrants. If migrants have more cancer than those who remain in Louisiana, the tendency would be to underestimate the SIR (and vice versa). We indirectly estimated relative health of migrants and non-migrants with information on Louisiana and nonLouisiana deaths and available address information. Among retired workers, migrants had the same rates as non-migrants for all deaths and all cancer deaths. Among non-retired workers who left, migrants had the same rate for all deaths and an apparently lower cancer rate than non-migrants (small numbers). Thus, available data argue against underestimated SIRs caused by poorer health of migrants.

Simulations were performed to estimate residual effects on SIRs after truncations of known non-Louisiana person-time. The simulation closest to cohort conditions assumed a $5 \%$ migrant portion, $80 \%$ of migrants' follow up time spent out of state, and a 1:1 ratio for migrant:non-migrant health. A $2.2 \%$ increase in effect was found when person-time after employment for known migrants was truncated (as was done in our analyses). An additional $2.8 \%$ increase in effect resulted when the simulation also accounted for migrants' cases of cancer occurring outside Louisiana. This suggested that our findings may be underestimated to a similar small degree because we could not ascertain migrants' cases of cancer.

Finally, an important limitation in interpretation of this study is its reliance on surrogates for work related exposures. We were not able to specify associations with any chemical exposures or process areas, and relations with specific exposures could have been missed in our analyses of broad groupings.

\section{Conclusion}

Although no single epidemiological study produces conclusive results, this investigation has provided new information to help answer questions raised by the earlier study. Workers first employed before 1950, who have most of the cancers in this cohort, seem to have slight increases in occurrence of LH malignancy, but not at the magnitude found in the mortality analysis and not including an excess of CLL. Work related patterns for $\mathrm{LH}$ malignancies are mixed, with an increased effect with long duration of employment, but no consistent association with jobs in different plants. Further interpretation is limited by different possible aetiologies among the diverse LH malignancy subtypes, and by our inability to control for potential confounding by non-work factors other than sex, age, race and period of diagnosis.

Results for those first employed in or after 1950 are based on fewer cases, but show no indication of an excess of LH malignancy. Numbers were too small for meaningful analysis of CLL and other LH subtypes in recent workers. No further study is recommended at this time. More time must elapse before recent workers in this cohort can be studied in more detail.

This study has shown the usefulness of state cancer registry information in studying an occupational cohort, and has shown how a company and a state agency can collaborate to more rigorously examine a suggestive finding from a mortality surveillance study.

We gratefully acknowledge Ms Lauri Mackenzie for assistance with preparation of the manuscript, Ms Celia Milano for programming support, and Ms Nancy Wojcik for data quality control. We thank Ms Patricia Andrews for LTR assistance on several occasions, Dr Mark Nicolich for statistical advice, and Dr John Bukowski for comments on the final draft. We are also most grateful to Dr Rob Schnatter for review and guidance durmost grateful to Dr Rob Schnatter for review and guidance dur-
ing the investigation and manuscript preparation and to Dr ing the investigation and manuscript preparation and to $\mathrm{Dr}$
Myron Harrison for his encouragement and support for the study from its inception. We are grateful to the Centers for Disease Control for support of LTR efforts. Finally, we wish to thank our External Advisory Committee, Drs Elizabeth Delzell and Curtis Mettlin, for their scientific oversight and thoughtful advice throughout the study.

1 Lewis RJ, Gamble JF, Jorgensen G. Mortality among three refinery/petrochemical plant cohorts. I. 1970-82 Active/ terminated workers. 7 Occup Environ Med (in press).

2 Hanis NM, Shallenberger LG, Donaleski D, et al. A retrospective mortality study of workers in three major US refineries and chemical plants. Part 1: Comparisons with US population. F Occup Med 1985:27:283-92.

3 Hanis NM, Shallenberger LG, Donaleski D, et al. A retrospective mortality study of workers in three major US refineries and chemical plants. Part II: Internal comparisons by geographic site, occupation, and smoking history. $\mathcal{f}$ sons by geographic site, occup
Occup Med 1985:27:361-9.

4 Shallenberger LG, Acquavella JF, Donaleski D. An updated mortality study of workers in three major United States refineries and chemical plants. Br F Ind Med 1992:49:34554 
5 Huebner WW, Schnatter AR, Nicolich MJ, et al. Mortality experience of a young petrochemical industry cohort: 1979-92 follow up study of US based employees. F Occup

6 Chemical Manufacturers Association's Epidemiology Task Group. Guidelines for good epidemiology practices for occupational and environmental epidemiologic research. Epidemiology Resource and Information Center (ERIC) Pilot Project. F Occup Med 1991:33:1211-8.

7 Chen VW, Correa CN, Wu XC, et al. Cancer Incidence in Louisiana, 1988-92. New Orleans: Louisiana Tumor Registry, 1996. (Cancer in Louisiana 1996;8:1).

8 Chen VW, Wu XC, Andrews PA, eds. Cancer incidence in North America, 1990-94. Vol 1. Incidence. Sacramento, CA North American Association of Central Cancer Registries, 1998.

9 Parkin DM, Muir CS, Whelan SI, et al, eds. Cancer incidence in five continents. Vol 6. Lyon, France: International Agency
for Research on Cancer 1992. (IARC Sci Publ No 120.)

10 Marsh G, Preininger ME. OCMAP: a user-oriented occupational cohort mortality program. American Statisticccupational cohort

11 Haenszel W, Loveland D, Sirkin MG. Lung cancer mortality as related to residence and smoking histories. $\mathcal{F}$ Natl Cancer Inst 1962:28;947-1001.

12 World Health Organisation. International classification of diseases for oncology. Geneva, Switzerland: WHO, 1976.

13 Percy C, Van Holten V, Muir C. International classification of diseases for oncology, $2 d$ ed. Geneva, Switzerland: World Health Organisation, 1990.

14 World Health Organisation. Ninth revision of the international statistical classification of diseases, injuries, and causes of death, 1977 ed. Geneva: WHO, 1977;1.

15 SEER program code manual, appendix b. Revised June, 1992. Surveillance, epidemiology and end results, (SEER). Bethesda, MD: National Cancer Institute, 1992.

16 Christie D, Robinson K, Gordon I, et al. A prospective study in the Australian petroleum industry. II. Incidence of canin the Australian petroleum industry

17 cer. Br f Ind Med 1991;48:511-14. workers, 1971-94. F Occup Environ Med 1998;40:675-9.

18 Delzell E, Austin H, Cole P. Epidemiologic studies of the petroleum industry. Fournal of Occupational Medicine: State of the Art Reviews 1988;3:455-73.

19 Wong O, Raabe GK. Critical review of cancer epidemiology in petroleum industry employees, with a quantitative metaanalysis by cancer site. Am f Ind Med 1989;15:283-310.

20 Greenwald P, Friedlander BR, Lawrence CE, et al. Diagnostic sensitivity bias: an epidemiologic explanation for an
21 Lynge E, Andersen A, Nilsson R, et al. Risk of cancer and exposure to gasoline vapors. Am $\mathcal{f}$ Epidemiol 1997:145:44958 .

22 Wen CP, Tsai SP, Weiss NS, et al. Long-term mortality study of oil refinery workers: V. Comparison of workers hired before, during, and after World War II (1940-5) with a discussion of the impact of study designs on cohort results. Am f Occup Med 1986;9:171-80.

23 Meinhardt TJ, Lemen RA, Crandall MS, et al. Environmental epidemiologic investigation of the styrene-butadiene rubber industry. Scand $\mathcal{F}$ Work Environ Health 1982;8:250-9.

24 Wong O, Raabe GK. Cell-type-specific leukemia analyses in a combined cohort of more than 208000 petroleum workers in the United States and the United Kingdom, 1937-89. Regul Toxicol Pharmacol 1995;21:307-21.

25 Satin KP, Wong O, Yuan LA, et al. A 50 year mortality follow up of a large cohort of oil refinery workers in Texas. $\mathcal{F}$ Occup Environ Med 1996;38:492-506.

26 Divine BJ, Hartman CM, Wendt JK. Update of the Texaco mortality study of 1947-93: Part II. Analyses of specific causes of death for white men employed in refining, causes of death for white men employed in refining,
research, and petrochemicals. Occup Environ Med 1999;56: $174-80$.

27 Checkoway H, Wilcosky T, Wolf P, et al. An evaluation of the associations of leukemia and rubber industry solvent exposures. Am f Ind Med 1984;5:239-49.

28 Malone KE, Koepsell TD, Daling JR, et al. Chronic ymphocytic leukemia in relation to chemical exposures. Am F Epidemiol 1989;130:1152-8.

29 Linet MS, Stewart WF, Van Natta ML, et al. Comparison of methods for determining occupational exposure in a casecontrol interview study of chronic lymphocytic leukemia. $\mathcal{F}$ Occup Med 1987;29:136-41.

30 Rushton L, Romaniuk H. A case-control study to investigate the risk of leukaemia associated with exposure to benzene in petroleum marketing and distribution workers in the United Kingdom. Environ Occup Med 1997;54:152-66.

31 Sathiakumar N, Delzell E, Cole P, et al. A case-control study of leukemia among petroleum workers. $\mathcal{F}$ Occup Environ of leukemia among pe

32 Hayes RB, Yin SN, Dosemeci M, et al. Benzene and the dose-related incidence of hematologic neoplasms in China. dose-related incidence of hematolog

33 Massoudi BL, Talbot EO, Day RD, et al. A case-control study of hematopoietic and lymphoid neoplasms: the role of work in the chemical industry. Am 7 Ind Med 1997;31:21-7.

34 Ries LAG, Kosary CL, Hankey BF, et al, eds. SEER cancer statistics review, 1973-95. Bethesda, MD: National Cancer Institute, 1998. 